\title{
Research on technological capabilities of double-electrode welding of long fillet welds
}

\author{
Andrei Fiveyskiy ${ }^{1, *}$, Aleksei Mosin ${ }^{1}$, Sergey Zverev ${ }^{1,2}$, and Ilya Polevoy ${ }^{2}$ \\ ${ }^{1}$ Federal State Autonomous Educational Institution of Higher Education "Ural Federal University \\ named after the first President of Russia B.N. Yeltsin ", Ekaterinburg, Russia, 620002 \\ ${ }^{2}$ SHTORM Co.Ltd, Ekaterinburg, Russia, 620100
}

\begin{abstract}
The article presents the results of a research of the technological capabilities of double-electrode submerged arc welding of elongated fillet welds with a leg of $8 \mathrm{~mm}$ or more in one pass while ensuring high-quality and stable formation of weld. As the result of the research we reviewed the features of the fillet weld formation during welding of metal strips with a thickness of $14 \mathrm{~mm}$ with different locations of the welding wires in the torch relative to the axis of the welded joint. Consequently we determined the best option in terms of the quality of the weld formation and increase in welding productivity as compared with the two-pass single-arc welding. The conditions and parameters of the singlepass double-electrode ("split electrode welding ") submerged arc welding are established, providing a welding speed of up to $35 \mathrm{~m} / \mathrm{h}$.
\end{abstract}

\section{Introduction}

Elements of bridge and building structures are load-bearing welded structures with a large number of elongated fillet welds, usually performed using automatic welding methods. It is known that for the normal formation of single-pass fillet welds with no edge preparation using PB welding position, the dimensions of legs should not exceed $9 \mathrm{~mm}$ [1]. Real production conditions, as a general rule, allow to obtain elongated welds of guaranteed quality only with a leg up to $7 \mathrm{~mm}$ under single-pass automatic submerged arc welding [2]. A fraction of the length of such welds in the annual program is usually only about $30 \%$. The remaining $70 \%$ are joints with fillet welds with a leg of $8 \mathrm{~mm}$, which are mainly produced under double-pass automatic submerged arc welding with a $2.0 \mathrm{~mm}$ diameter welding wire and welding currents of approximately 350 A with a welding speed of about $18 \mathrm{~m} / \mathrm{h}$. It is obvious that the presented production technology requires an increase in welding productivity, i.e. research of the possibilities of using single-pass welding to produce $8 \mathrm{~mm}$ legs, while ensuring high-quality and stable formation of elongated fillet welds. The simplest known option to increase welding productivity is to implement doubleelectrode welding or the so-called "split electrode welding" [3]. Interest in research of the

\footnotetext{
*Corresponding author: amf2@mail.ru
} 
technological capabilities of this welding method has recently reappeared, however, mainly with the aim of studying the processes of formation of heat- and corrosion-resistant deposited metal [4], when surfacing special materials [5], as well as at production of butt welds of petrochemical vessels [6] and special equipment [7].

\section{Experimental procedure}

Automatic submerged arc welding was carried out according to the scheme shown in Fig. 1., a welding portal with an A6 automatic welding machine and a welding power source LAF 1001 (ESAB), using a welding torch to feed two wires simultaneously, as well as an automatic tracking and maintaining the positioning of the torch against the welding joint. As work-pieces, T-shaped elements were taken, assembled on tacks from two strips 200 $\mathrm{mm}$ wide, $14 \mathrm{~mm}$ thick from 10CrSiNiCu steel for T- joint (T1 according to GOST 871379).

Q

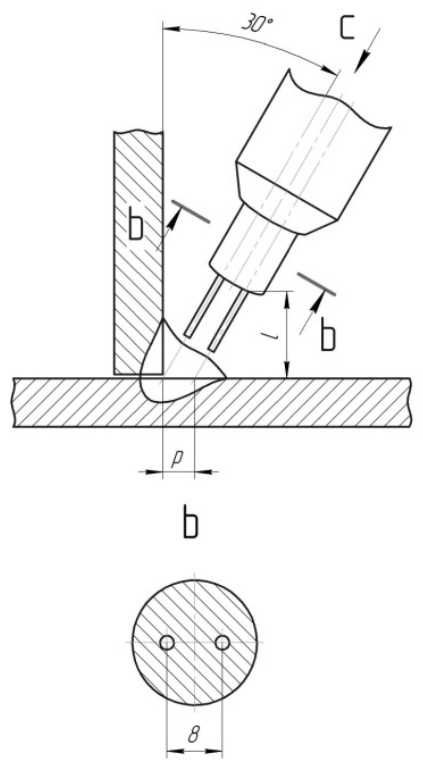

[
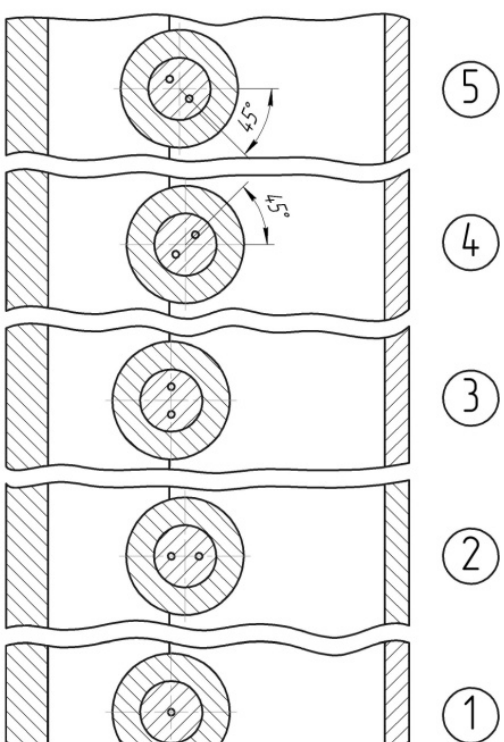

Fig. 1. The parameters of the welding joint and the relative position of the torch (a), the cross section of a contact tip (b) and different positions the welding wires against the work-pieces (c).

Five workpieces are welded with a welding wire Sv-08GA-O ( $\mathrm{C} \leq 0.1$; Mn 0.8-1.1; $\mathrm{Si} \leq 0.06$; $\mathrm{Cr} 0.1$; Ni 0.25; S 0.25; P 0.03) (GOST 2246-70) with a diameter of $2 \mathrm{~mm}$ under flux UF-02 (EN ISO 14174) under the following conditions (Fig.1 (c)):

1) single-electrode double-pass welding;

2) double-electrode single-pass welding (with wires located along the seam);

3) double-electrode single-pass welding (with wires located across the seam);

4) double-electrode single-pass welding with the lower inclined under acute angle (angle $45^{\circ}$ );

5) double-electrode single-pass welding with lower wire inclined under obtuse angle (angle $45^{\circ}$ ). 
In all cases of welding, the welding torch was installed at an angle of $30^{\circ}$ (Fig. 1 (a)) against the web of a work-piece, with a stick-out $l$ of $25 \mathrm{~mm}$. Double-electrode welding was performed using a special contact tip with a distance of $8 \mathrm{~mm}$ between the wires (Fig. 1 (b)). Welding modes and the size of the actual position of electrode wires $p$ against the work-pieces (Fig. 1 (a)) are given in Table 1.

Table 1. Welding mode parameters

\begin{tabular}{|c|c|c|c|c|c|}
\hline Number of workpiece (sample) & 1) & 2) & 3) & 4) & 5) \\
\hline Position of electrodes $p, \mathrm{~mm}$ & $10 / 0 *$ & 5 & 9 & 8 & 6 \\
\hline Welding current, A & 300 & 850 & 850 & 850 & 850 \\
\hline Voltage, V & 28 & 29 & 29 & 29 & 29 \\
\hline Welding speed, $\mathrm{m} / \mathrm{h}$ & 23 & 25 & 25 & 25 & 35 \\
\hline
\end{tabular}

*first pass/second pass

From the welded work-pieces we cut out the samples and prepared macro sections to determine the formation parameters for the welds. The studied parameters are shown in Fig. 2.

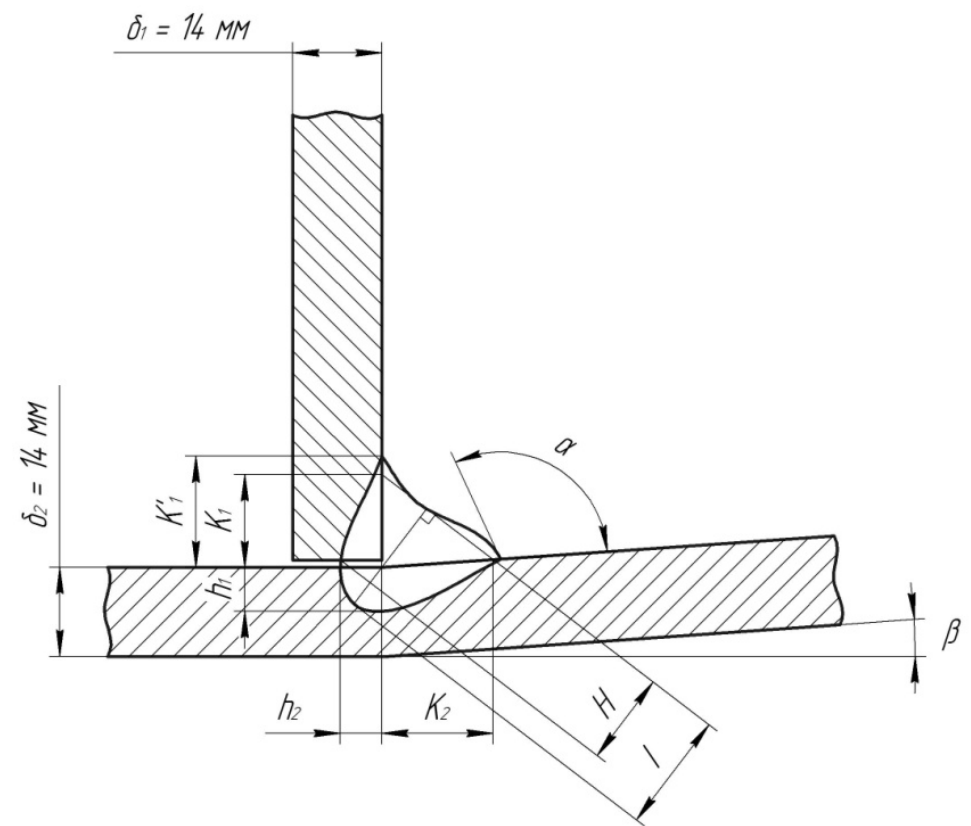

Fig. 2. The parameters of the cross section of welding joints under research.

\section{Results and reading}

The external formation and macro sections of the obtained samples in accordance with the numbering given above are shown in Fig. 3 . 


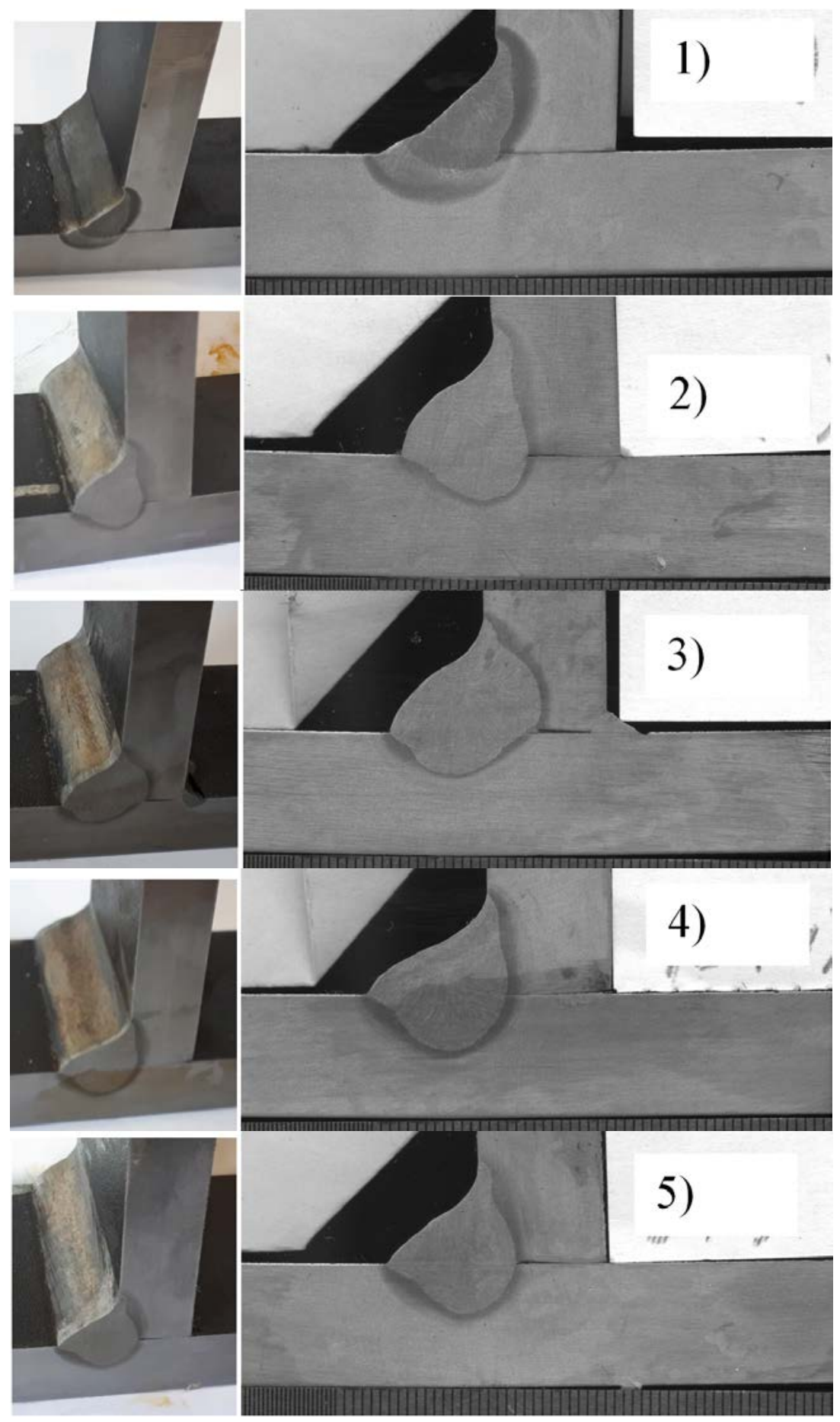

Fig. 3. External view of the welded samples and their cross section - macro section in accordance with a given numbering.

Summarizing the measurements of macro sections, the results are presented, which are presented in Table 2. 
Table 2. The parameters of the obtained welds of the workpieces.

\begin{tabular}{|c|c|c|c|c|c|c|c|c|c|c|}
\hline $\begin{array}{c}\text { Number } \\
\text { of } \\
\text { workpiece }\end{array}$ & $\begin{array}{c}\mathbf{K}_{\mathbf{1}}, \\
\mathbf{m m}\end{array}$ & $\begin{array}{c}\mathbf{K}_{2}, \\
\mathbf{m m}\end{array}$ & $\begin{array}{c}\mathbf{h}_{\mathbf{1}}, \\
\mathbf{m m}\end{array}$ & $\begin{array}{c}\mathbf{h}_{2}, \\
\mathbf{m m}\end{array}$ & $\begin{array}{c}\mathbf{K}_{\mathbf{1}}{ }^{\prime}, \\
\mathbf{m m}\end{array}$ & $\mathbf{\alpha}^{\mathbf{o}^{\prime}}$ & $\boldsymbol{\beta}^{\mathbf{0}}$ & $\begin{array}{c}\mathbf{H}, \\
\mathbf{m m}\end{array}$ & $\begin{array}{c}\mathbf{I}, \\
\mathbf{m m}\end{array}$ & $\begin{array}{c}\text { Wedling } \\
\text { Deffect - } \\
\text { Acceptable / } \\
\text { unacceptable }\end{array}$ \\
\hline 1$)^{*}$ & 9,3 & 10,6 & 0,8 & 4,2 & 12,7 & 148 & 1,3 & 7,8 & 7,8 & $\begin{array}{c}\text { undercut } 0,2 \\
\text { mm - } \\
\text { unacceptable }\end{array}$ \\
\hline 2$)$ & 11,6 & 10,8 & 3,5 & 5,8 & 13,4 & 99 & 2,0 & 10,5 & 11,7 & $\begin{array}{c}\text { overlap - } \\
\text { unacceptable }\end{array}$ \\
\hline 3$)$ & 11,0 & 11,0 & 6,2 & 4,5 & 13,2 & 97 & 1,5 & 12,3 & 11,2 & $\begin{array}{c}\text { overlap - } \\
\text { unacceptable }\end{array}$ \\
\hline 4$)$ & 9,3 & 13,3 & 2,1 & 6,2 & 11,8 & 120 & 1,0 & 8,7 & 10,6 & $\begin{array}{c}\text { leg asymmetry - } \\
\text { unacceptable }\end{array}$ \\
\hline 5$)$ & 8,2 & 10,2 & 3,8 & 5,4 & 10,4 & 123 & 1,5 & 8,8 & 10,4 & $\begin{array}{c}\text { leg asymmetry - } \\
\text { acceptable }\end{array}$ \\
\hline
\end{tabular}

All experimentally welded samples of the T-joint from sheets with a thickness of 14 $\mathrm{mm}$ were obtained with a leg exceeding the required size of $8 \mathrm{~mm}$. Allowable tolerances for such joint of $+2.0 \mathrm{~mm}$ and $-1.0 \mathrm{~mm}$ were exceeded only with sample 2) - with wires located along the seam one after the other. A comparative analysis of the measurements of the welds obtained showed the following.

The first sample has an almost symmetrical leg - in the ratio of about $9 / 10 \mathrm{~mm}$, smooth contact to the web and the flange, minimal reinforcement and relatively small angular deformation - angle $\beta=1.3^{\circ}$. However, there is a small undercut, the smallest penetration is less than $8 \mathrm{~mm}$, small fusion with the web, HAZ is the biggest, and the welding speed is the slowest.

On the second sample, the maximum leg was obtained $-\mathrm{K}_{1}=11.6 \mathrm{~mm}$, and approximately the same $\mathrm{K}_{2}=10.8 \mathrm{~mm}$ and a comparable penetration of $11.7 \mathrm{~mm}$, but the shape of the abutment of the leg to the flange can be classified as an unacceptable defect overlap (angle $\alpha=99^{\circ}$ ) with high reinforcement, and also on this sample the greatest angular deformation.

The third sample has the most symmetrical leg in the ratio of $11 / 11 \mathrm{~mm}$, the deepest penetration $\mathrm{H}$, equals to $12.3 \mathrm{~mm}$, the largest fusion of the web along the root of the seam, almost equal to half of the web's thickness, while there is a large reinforsement of the seam and the largest of all overlap on the flange.

Samples 4) and 5) are distinguished by the presence of a defect in the form of an unequal leg, called asymmetry, but it can be considered unacceptable only on a sample 4), on which the sizes of legs differ by 1.5 times. Both samples have low reinforcement and smooth abutment of the leg to the flange and the web, but sample 4) has the smallest angular deformation. Sample 5) is preferable due to a more symmetrical form of penetration, minimal reinforcement and penetration depth that exceeds the size of the leg. In this case, sample 5) was obtained at a higher welding speed than the others. 


\section{Conclusion}

The results of the experiment showed that under double-electrode submerged arc welding of T-joints from $14 \mathrm{~mm}$ thick sheets with no edge preparation, it was possible to obtain welds of satisfactory quality with a leg of more than $8 \mathrm{~mm}$ at a current of $850 \mathrm{~A}$, voltage $29 \mathrm{~V}$ with a welding speed of $35 \mathrm{~m} / \mathrm{h}$ with a the location of welding wires with a diameter $2.0 \mathrm{~mm}$ in the torch at an angle of $45^{\circ}$ against the axis of the weld with the lower wire inclined under obtuse angle.

\section{References}

1. Paton B.E. Technology of electric fusion welding of metals and alloys] M.: Mashinostroyeniye (1974).

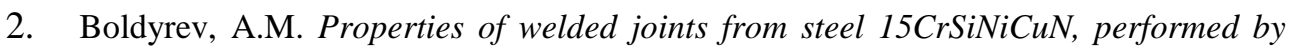
automatic welding in a mixture of shielding gases under flux A. M. Boldyrev, I.I. Muravyov, S.V. Guryev, V.M. Goritsky: Scientific Herald of the Voronezh State Autonomous University of Ukraine. Construction and architecture, v.1 (25), pp. 16-25 (2012).

3. Y. Xiuzhi. Twin-wire Submerged Arc Welding Process of a High-strength Low-alloy Steel/Xiuzhi Y., Qinghua X., Niandong Y., Xinhua X.//Journal of Wuhan University of Technology-Mater. Sci. Ed., v. 26, pp. 114-117 (2011).

4. Yelsuk S.K., Zorin I.V., Sokolov G.N., Dubtsov Y.N., Litvinova T.R., Fastov S.A., Fetisov V.A. Technological features of the formation of metal deposited by a split electrode Bulletin of the Volgograd State Technical University, v. 10, pp. 122-125 (2017).

5. Zorin I.V., Yelsukov S.K., Sokolov G.N. [Research of the process of surfacing with a split electrode of Inconel 625 alloy Svarochnoye proisvodstvo, v. 11, pp. 9-15 (2018).

6. Elsukov S.K., Zorin I.V., Sokolov G.N., Artemyev A.A., Fastov S.A., Kazymov F.A. Effect of multi-pass split electrode submerged arc welding on the structure and properties of low-carbon steel welds. Bulletin of the Volgograd State Technical University, v. 9, pp. 133-137 (2018).

7. Sholokhov M.A. [The development of elements of the theory of weld formation and the technological foundations of multi-pass welding with a consumable electrode over the narrow gap of the body structures of special equipment from high-strength steels abstract. dis. doct. tech. sciences. Moscow, (2016). 